\title{
DIREITO DE INFORMAÇÃO JORNALÍSTICA E IMPRENSA NO ESTADO DEMOCRÁTICO DE DIREITO
}

\section{JOURNALISTIC INFORMATION LAW AND PRESS AS DEMOCRATIC RIGHT}

\author{
${ }^{1}$ Rômulo Magalhães Fernandes \\ 2 Anna Carolina de Oliveira Azevedo
}

\section{RESUMO}

O presente artigo tem como objetivo refletir sobre o direito de informação jornalística e a atuação da imprensa no Estado Democrático de Direito. A Constituição de 1988 compreende o direito fundamental à informação de forma ampla, em suas diferentes dimensões: direito de informar, direito de se informar e o direito de ser informado, e, ao mesmo tempo, também admite a proteção específica à liberdade de informação jornalística. Nessas duas perspectivas, o pano de fundo é semelhante, o respeito dos princípios da dignidade da pessoa humana e do Estado Democrático de Direito. A partir de uma metodologia teórica, busca-se estabelecer quatro eixos centrais de discussão. No primeiro, analisa-se o movimento de mudança da noção de liberdade de imprensa à liberdade de informação jornalística. No segundo, discorrese sobre a constitucionalização do direito de liberdade de imprensa e de informação e, na etapa seguinte, sobre a liberdade de informação jornalística como direito autônomo na Constituição brasileira de 1988. Por derradeiro, no quarto eixo, abordam-se os limites internos e externos da liberdade de informação jornalística. Com isso, conclui-se, que a atividade jornalística, apesar da sua proteção na ordem constitucional, não é absoluta, e deve se preocupar sempre com a conciliação e a harmonização dos demais direitos fundamentais.

Palavras-chave: Direito de informação, Estado democrático de direito, Imprensa, Liberdade de informação jornalística

\begin{abstract}
This article aims to reflect on the right of press and the role of the press in a democratic state. The 1988 Constitution contains the fundamental right to information broadly in its different dimensions: the right to inform, the right to inform and the right to be informed, and at the same time, also admits specific protection to freedom of press. These two perspectives, the backdrop is similar, respect the principles of human dignity and democratic rule of law. From a theoretical methodology, seeks to establish four central themes of discussion. In the first, it analyzes the change of movement of the notion of freedom of the press to freedom of press. In the second, it talks about the constitutionalization of the right to freedom of press and information, and the next step on the freedom of press as autonomous rights in the Brazilian Constitution of 1988. Last, the fourth axis, it address the internal and external limits of
\end{abstract}

\footnotetext{
${ }^{1}$ Doutorando em Direito Público na Pontifícia Universidade Católica de Minas Gerais. Advogado. Pontifícia Universidade Católica de Minas Gerais - PUC/MG, Minas Gerais. Brasil - E-mail: romulopn@yahoo.com.br 2 Mestranda em Administração Pública na Escola de Governo da Fundação João Pinheiro. Auditora Seccional da Fundação Rural Mineira. Escola de Governo da Fundação João Pinheiro - FJP/MG, Minas Gerais. Brasil E-mail: annac.azevedo@hotmail.com
} 
freedom of press. Thus, it concludes, the journalistic activity, despite its protection in the constitutional order, is not absolute, and must always worry about the reconciliation and harmonization of other fundamental rights.

Keywords: Right to information, Democratic state, Press, Freedom of press 


\section{INTRODUÇÃO}

Com a promulgação da Constituição da República de 1988 (CR/1988), a Constituição Cidadã, inaugura-se um novo paradigma no Brasil, em que a interpretação das normas deve, essencialmente, considerar os ditames constitucionais e o conjunto de direitos fundamentais.

Nesse cenário, a relação entre os direitos fundamentais e a Constituição torna-se "orgânica", de estreita unidade, assumindo um duplo aspecto: primeiro, pela realização efetiva dos direitos fundamentais, segundo, pela legitimação dos processos de comunic ação entre indivíduos, órgãos e instituições públicas e privadas que regerá o fundamento da própria Constituição (CRUZ, 2001, p. 196).

Dentre os direitos fundamentais consagrados, destaca-se a liberdade de informação entendida como um direito da pessoa de informar, de exteriorizar sua opinião (GODOY, 2001, p. 58), e também como um direito coletivo, que inclui o direito do povo de ser bem informado (NOBRE, 1988, p. 33).

O texto constitucional compreende o direito fundamental à informação de forma ampla, em diferentes dimensões: direito de informar, direito de se informar e o direito de ser informado, e, ao mesmo tempo, também admite a proteção específica à liberdade de informação jornalística. Nessas duas perspectivas, o pano de fundo é semelhante, o respeito dos princípios da dignidade da pessoa humana e do Estado Democrático de Direito .

Se, no passado, a principal preocupação do Estado liberal era contrapor o poder dos governos e seus instrumentos de censura à imprensa, no Estado Democrático de Direito contemporâneo há uma preocupação crescente com o conflito entre liberdades individuais, ou ainda, com os excessos de uma imprensa empresarial poderosa que pode devassar intimidades e deturpar a opinião pública (CARVALHO, 1994, pp. 13-14).

Nesse sentido, o presente trabalho objetiva refletir sobre o direito de informação jornalística e a atuação da imprensa no Estado Democrático de Direito.

Para tanto, utiliza-se a metodologia teórica, com a sucessão de quatro eixos centrais de discussão. No primeiro, analisa-se o movimento de mudança da noção de liberdade de imprensa à liberdade de informação jornalística. No segundo, discorre-se sobre a constitucionalização do direito de liberdade de imprensa e de informação e, na etapa seguinte, sobre a liberdade de informação jornalística como direito autônomo na Constituição brasileira 
de 1988. Por derradeiro, no quarto eixo, abordam-se os limites internos e externos da liberdade de informação jornalística.

\section{DA LIBERDADE DE IMPRENSA À LIBERDADE DE INFORMAÇÃO JORNALÍSTICA}

Desde tempos remotos, os homens procuravam se entender por intermédio de símbolos e sinais e, assim, passavam a diferenciar representações artístico-estéticas daquelas de caráter predominantemente comunicativas (MIRANDA, 1959, p. 3).

É apenas a partir do século XIV, contudo, que o conceito de imprensa ganha maior precisão, sendo caracterizado, em sentido amplo, como "todos os produtos impressos" (MIRANDA, 1959, p. 16), e, em sentido restrito, como “jornais e periódicos destinados a larga divulgação" de leitores (MIRANDA, 1959, p. 17).

Duas condições históricas são fundamentais para que a imprensa alcançasse tal definição. A primeira, dỉ respeito à introdução de um novo modo de produção, em que "a notícia não somente acompanha o trânsito de mercadorias, mas torna-se, também uma delas na criação de mercados e feiras do capitalismo iniciante" (MARCONDES FILHO, 1984, p. 14). A segunda condição, concomitante à primeira, é o desenvolvimento de novas tecnologias na Europa nos séculos XIV e XV, capazes agilizar a confecção de materiais impressos.

Nesse contexto, diante da importância registrada na doutrina ocidental, vale a menção de João Gensfleish de Sorgeloch, mais conhecido como Gutenberg, que, em 1436, inventou os caracteres tipográficos e fez funcionar a primeira prensa de imprimir (MIRANDA, 1958, p. 5).

Além da imprensa, a origem da atividade jornalística possui uma relação direta com o processo de consolidação do modo de produção capitalista.

No período mercantilista, o que se observa é a comercialização da informação como notícia. Isso, a partir de edições regulares de conteúdo puramente técnico, como dados climáticos, curiosidades, temas pitorescos e relatos econômicos. Aqui, ainda não se visualizava uma atividade jornalística propriamente dita (MARCONDES FILHO, 1984, p. $15)$. 
Num momento posterior, de surgimento das bases do capitalismo, o ato da notícia ganha novos contornos, representando, em última instância, a afirmação de uma nova classe em ascensão: a burguesia. A notícia, agora conduzida em meio de uma atividade jornalíst ica, passa a considerar o uso do veículo impresso não apenas para fins econômicos, mas também ideológicos e políticos (MARCONDES FILHO, 1984, p. 16).

Dentro desta ordem política e social transformada durante a fase mercantilista (cuja forma em boa parte se expressa no fato de que nela os momentos do político e do social aparecem separados), o segundo elemento da relação de circulação capitalista iniciante desenvolve, então, uma força explosiva singular, a imprensa (MARCONDES FILHO Apud HABERMAS, 1984, p. 15).

A origem da imprensa e da atividade jornalística, nesse sentido, é influenciada pelos movimentos jurídicos e filosóficos de ascensão da burguesia, sendo concebidos com "o mesmo germe do liberalismo, do absoluto respeito à propriedade privada particular, do individualismo exacerbado, do Estado meramente assegurador desses valores" (CARVALHO, 1994, p. 2).

No âmbito do Direito, em específico, as Declarações do século XVIII e XIX, percebe-se uma predominância dos direitos de primeira dimensão (BONAVIDES, 1993, p. 525), representados, sobretudo, pelos direitos à vida, à liberdade, à igualdade (formal) e à segurança (STROPPA, 2010, p. 33). Nesse período, "afirmaram-se os direitos de liberdade, isto é, todos aqueles direitos que tendem a limitar o poder do Estado e a reservar para o indivíduo, ou para os grupos particulares, uma esfera de liberdade em relação ao Estado" (BOBBIO, 1992, p. 32).

No decorrer dos anos, os diferentes povos passam a acrescentar novas exigências ao Estado de Direito, as quais não poderiam ser compatibilizadas pela concepção liberal (STROPPA, 2010, p. 122). Surge, assim, um processo de configuração do Estado Democrático de Direito que, no âmbito de liberdades e garantias, admite a possibilidade de uma perspectiva positiva do poder estatal, mesmo que ainda secundária, onde este contribui na organização, regulação e prestação de ações que têm em vista a função social consagrada no texto constitucional (STROPPA, 2010, p. 101).

Muitos autores ${ }^{1}$, atentos ao avanço dos meios de comunicação de massa, buscaram 
atualizar o conceito de imprensa. A tífulo de exemplo, para Carlos Alberto Rabaça e Gustavo Barbosa (2001, p. 379) a imprensa extrapola o sentido original de impresso e passa a ser caracterizado como processos de difusão jornalística por veículos impressos ou eletrônicos.

Os documentos internacionais e as Constituições mais recentes, todavia, não tem se limitado a ampliar o conceito de imprensa e sim propor a sua substituição pela noção de informação. Desse modo, os textos legais não se contentam apenas em garantir a liberdade de imprensa, mas também buscam proteger o direito e o acesso à informação, bem como o direito de informar do cidadão (CARVALHO, 1994, p. 24).

\section{O DIREITO CONSTITUCIONAL DE LIBERDADE DE IMPRENSA E DE INFORMAÇÃO}

Os Estados Unidos da América e a França foram os primeiros países a constitucionalizar o direito à liberdade de imprensa (NUNES JÚNIOR, 1997, p. 36). Nesse período, imprensa ainda era o termo que representava a difusão de informações e opiniões.

Isso começa a mudar à medida em que as Constituições dos Estados e os diversos documentos multilaterais adotam a expressão jurídica da liberdade de informação, englobando a transmissão de informações e ideias por todos os meios de comunicação de massa independentemente de fronteiras (STROPPA, 2010, pp. 148-149).

A Declaração de Direitos do estado da Virgínia, de 1776, em seu artigo 12, reconhece explicitamente, pela primeira vez na história das Declarações, a liberdade de expressão por intermédio da imprensa (SILVA, 2000, p. 149), considerando esta como um dos "grandes baluartes da liberdade" (EUA Apud SILVA, 2000, p. 149).

\footnotetext{
${ }^{1}$ Luís Gustavo Grandinetti Castanho de Carvalho (1999, pp. 81-110), Tatiana Stroppa (2010, pp. 146-206), José Afonso da Silva (1998, pp. 249-251), Vera Maria de Oliveira Nusdeo Lopes (1997, pp. 163-221), Vidal Serrano Nunes Júnior (1967, pp. 36-38), Sérgio Ricardo de Souza (2008, pp. 89-108; 2013, pp.11-14), entre outros, privilegiam a nomenclatura liberdade de informação jornalística em comparação à liberdade de imprensa.
} 
Anos depois, em 1791, a Emenda N No. 1 da Constituição dos Estados Unidos da América contempla a liberdade de expressão e de imprensa de maneira categórica, afirmando que o Congresso não fará lei alguma "que restrinja a liberdade da palavra, ou de imprensa" (EUA Apud SILVA, 2000, p. 149). Essa Emenda foi decisiva para influenciar outros países do Ocidente do globo, que passaram a inserir a liberdade de imprensa no arcabouço jurídico de suas kgislações (SOUZA, 2008, p. 90).

Na França, em 1789, a Declaração dos Direitos dos Homens e do Cidadão, nos seus artigos 10 e 11, reafirma a liberdade de expressão e de imprensa, bem como os limites de tais liberdades:

10. Ninguém pode ser molestado por suas opiniões, incluindo opiniões religiosas, desde que sua manifestação não perturbe a ordem pública estabelecida pela lei.

11. A livre comunicação das ideias e das opiniões é um dos mais preciosos direitos do homem; todo o cidadão pode, portanto, falar, escrever, imprimir livremente, respondendo, todavia, pelos abusos desta liberdade nos termos previstos na lei (FRANÇA Apud SILVA, 2000, p. 150).

A Declaração dos Direitos dos Homens, mesmo que de forma implícita, contempla o direito à informação, de onde alguns doutrinadores extraem a compreensão de que, particularmente no último artigo, encontra-se a origem do direito fundamental à informação (SILVA, 2000, p. 150).

A primeira vez que o direito a receber informações é expressamente reconhecido ao lado das liberdades de expressão e de imprensa - é no artigo 19 da Declaração Universal dos Direitos Humanos de 1948 (SILVA, 2000, pp. 150-151), ao ponto que afirma que toda pessoa tem direito à liberdade de opinião e expressão, sendo incluído em tal direito "a liberdade de, sem interferências, ter opiniões e procurar, receber e transmitir informações e ideias por quaisquer meios e independentemente de fronteiras" (ONU, 1948).

A mesma proteção jurídica ocorre em documentos internacionais posteriores, como o Pacto Internacional dos Direitos Civis e Políticos de 1966 (artigo 19), o Convênio Europeu para Proteção dos Direitos Humanos e das Liberdades Fundamentais de 1950 (artigo 10.1) e a Convenção Americana de Direitos Humanos de 1969 (artigo 13.1), os quais acolhem os direitos fundamentais da liberdade de expressão, de imprensa e de informação.

Assim como a Decharação Universal dos Direitos Humanos de 1948 (DUDH), os documentos internacionais acima citados ainda não reconheciam o caráter autônomo do direito de informação, ficando este subordinado ao direito de expressão (LOPES, 1997, p. 
183). Apesar disso, tais textos contribuíram sensivelmente para o processo de reconhecimento do direito de informação, na medida em que apresentavam um "bifacialidade do direito de expressão, prescrevendo tanto a liberdade de transmitir e comunicar como a de procurar e receber informações" (SCLAENDER Apud LOPES, 1997, p. 184).

No século XX, não sem a resistência de alguns doutrinadores e juristas mais ligados à concepção liberal, o direito de liberdade de informação passa a ter reconhecida sua autonomia em face aos direitos de liberdade de expressão e de imprensa, sendo merecedor de uma sistematização própria (LOPES, 1997, p. 185). Esse foi o caminho adotado, por exemplo, pelas Constituições da Espanha (artigo 20), de Portugal (artigo 37), da Nicarágua (artigo 66) e da antiga República Socialista da Iugoslávia (artigo 168) (LOPES, 1997, pp. 185-186).

De modo geral assim evoluiu a liberdade de imprensa - ou o termo mais amplo e complexo "liberdade de informação" - ora como direito fundamental absoluto, ora como direto fundamental relativizado por um conjunto de limitações estipuladas nas Constituições dos países (CARVALHO, 1994, p. 18).

As diversas correntes jurídicas e filosóficas adotas pelos movimentos de defesa dos Direitos Humanos, desde o Iluminismo no século XVIII, tem contribuído para a inclusão de liberdades vinculadas à comunicação e à expressão na ordem constitucional dos países.

O Brasil, por sua vez, não fica imune a essa tendência e, na esteira da DUDH, reconhece na sua Lei Maior o valor dos meios de comunicação para a manutenção de uma sociedade bem informada e a indispensabilidade da liberdade de informação jornalística (SOUZA, 2008, p. 97).

\section{A LIBERDADE DE INFORMAÇÃO JORNALÍSTICA E A CONSTITUIÇÃO DE 1988}

A "matriz da liberdade de imprensa ou de informação é a liberdade de manifestação de pensamento" (CARVALHO, 1994, p. 25), sendo a liberdade de informação uma "ramificação desta originada" (CARVALHO, 1999, p. 26).

Se no Estado de Direito a liberdade de informação era tida como um apêndice à liberdade de expressão ou de opinião, no processo de consolidação do paradigma do Estado Democrático de Direito nota-se uma vabrização do estabelecimento de regras próprias da liberdade de informação com o objetivo de assegurá-la (LOPES, 1997, p. 197). 
Tatiana Stroppa afirma que "o direito ou liberdade de informação agrega não apenas a liberdade do emissor, mas também o direito do destinatário de se informar e de ser informado" (STROPPA, 2010, p. 71), compreendendo, assim, num mesmo direito, "o direito de informar, de se informar e de ser informado" (STROPPA, 2010, p. 71).

Com o desenvolvimento dos meios de comunicação de massa, o direito à informação, que tem como titular "a população ou a sociedade globalmente considerada" (LOPES, 1997, p. 195), estabelece um conjunto de regras, inclusive sobre a informação típica do jornalismo. É esta liberdade de informação jornalística, centrada na liberdade de informação e com características modernas, que é capaz de superar a velha noção de liberdade de imprensa (SILVA, 1998, p. 249).

A liberdade de informação jornalística, diferentemente de outras informações qualificadas como publicitárias ou de entretenimento (FERREIRA, 1997, p. 94), possui proteção juríd ica quando:

É publicada ou transmitida por meio de comunicação de grupo ou de massa (MCM) em forma de notícia, artigo, comentários, entrevista ou reportagem em função (ou efeito) de atualização ou formação de opiniões (informação atualizadora), ou de vulgarização científica e tecnológica (informação pedagógica ou instrutiva) (FERREIRA, 1997, p. 94).

Em outras pahavras, a informação jornalística tem, como objeto, dois núcleos básicos: a notícia e a crítica (STROPPA, 2010, p. 162), alcançando qualquer forma de difusão de matérias, comentários e opiniões por qualquer veículo de comunicação social (SILVA, 1999, p. 249).

Para os objetivos deste artigo, utiliza-se o termo cunhado no próprio texto constitucional de "liberdade à informação jornalística", tendo em vista a sua amplitude e capacidade de delimitar as especificidades das informações jornalísticas difundidas pelos meios de comunicação de massa, como programas de televisão, rádio, sites, revistas, etc.

Na perspectiva do Direito Constitucional brasileiro, especialmente com o advento da Constituição da República de 1988, é perceptível a preocupação do constituinte em garantir uma ampla liberdade de informação e o enfretamento de práticas de censura. Afinal de contas, poucos anos antes, o Brasil conviveu por um logo período ditatorial, em que foi comum o uso da força e dos institutos jurídicos para "silenciar" manifestações contrárias ao regime e censurar os meios de comunicação. 
A título de exemplo, cita-se a instauração do Ato Institucional $N^{\circ}$ 5, de 1968, que, no seu Preâmbulo, afirmava que o governo ditatorial comprometia-se com o "combate à subversão e às ideologias contrárias ao povo brasileiro" (BRASIL, 1968).

Esse contexto refletiu diretamente na CR/1988, a qual firmou, de forma categórica, a possibilidade do estabelecimento de um livre fluxo de informações no país (STROPPA, 2010, p. 147). No que se refere à liberdade da atividade jornalística, assumida em diferentes dimensões (SOUZA, 2008, p. 101), a Constituição dispõe que "é livre a expressão da atividade intelectual, artística, cientiffica e de comunicação, independentemente de censura ou licença" (BRASIL, 1988), bem como "é assegurado a todos o acesso à informação e resguardado o sigilo da fonte, quando necessário ao exercício profissional” (BRASIL, 1998).

Apesar da amplitude da liberdade assegurada no texto constitucional, vale enfatizar que os direitos constitucionais de liberdade de expressão, de informação ou de imprensa, não são absolutos, encontrando limites na própria Constituição (BARROSO, 2007, p. 84).

Em outros termos, a proteção constitucional à liberdade de informação "não implica salvo-conduto" para que o proprietário do veículo de informação ou o jornalista agrida impunemente direitos atribuídos à pessoa (CALDAS, 1997, p. 67) ou, ainda, deixe de considerar na atividade jornalística princípios que lhe são próprios, como é caso do dever da veracidade da informação (LOPES, 1997, p. 2007).

\footnotetext{
${ }^{2}$ Artigo 220, parágrafo $1^{\circ}$, da Constituição da República de 1988 afirma que: "Nenhuma lei conterá dispositivo que possa constituir embraço à plena liberdade de informação jornalística em qualquer veículo de comunicação de massa, observando os dispostos no art. 5\%, IV, V, X, XIII e XIV”'(BRASIL, 1988, grifo nosso).
} 


\section{OS LIMITES DA LIBERDADE DE INFORMAÇÃO JORNALÍSTICA}

O desenvolvimento da atividade jornalística livre representa um verdadeiro pressuposto para a existência do atual Estado Democrático de Direito brasileiro. Com efeito, sem a liberdade de informação mediante os veículos de comunicação de massa, a noção de democracia que se tem hoje seria completamente diferente (GUERRA, 2005, p. 248).

O exercício desse direito de informar, em último nível, é o que "define o regime democrático de um país” (LEÃO, 1961, p. 20), na medida em que, de forma recíproca, "quanto mais a democracia é servida pela imprensa, mais a imprensa é servida pela democracia" (STF, 2009, p. 31, grifo nosso). Desse modo, a liberdade de informação pelos meios de comunicação de massa, ou de grupos, influencia direta e indiretamente e dá conteúdo às sociedades democráticas contemporâneas, uma vez que possibilita o intercâmbio de ideias, o controle do poder e o diálogo político da coletividade (HONÓRIO et. al, 2008, p. 1910).

A Constituição de 1988, não alheia a essa relação entre democracia e liberdade de informação, caracteriza, no seu artigo $5^{\circ}$, incisos IV, IX, e XIV, a necessidade de proteção da liberdade nos seus diferentes aspectos: a livre manifestação de pensamento, a livre expressão da atividade artística, científica e de comunicação e o direito de informação.

Isso, contudo, não torna as atividades típicas da imprensa, compreendidas aqui num sentido amplo, isentas de limites ou controle quanto a eventuais abusos que venham cometer. Portanto, a liberdade de informação jornalística, como qualquer outra liberdade, não é absoluta.

O artigo 220, caput, da CR/1988, por exemplo, prescreve que "a manifestação do pensamento, a criação, a expressão e a informação, sob qualquer forma, processo ou veículo não sofrerão qualquer restrição, observado o disposto nesta Constituição" (BRASIL, 1988, grifo nosso). Nota-se, nesse dispositivo, a menção à possibilidade de restrições definidas pelo próprio texto constitucional.

Ainda no artigo 220, o parágrafo primeiro dispõe que "nenhuma lei conterá dispositivo que possa constituir embaraço à plena liberdade de informação jornalística em qualquer veículo de comunicação social, observado o disposto no artigo $5^{\circ}$, incisos IV, $\mathrm{V}, \mathrm{X}$, XIII e XIV” (BRASIL, 1988, grifo nosso). 
Sobre tal dispositivo legal, vale a lembrança da Ação Direita de Inconstitucionalidade $\mathrm{N}^{\circ}$. $869 / \mathrm{DF}^{3}$, que declarou inconstitucional trecho do artigo $247, \S 2^{\circ}$, do Estatuto da Criança e do Adolescente (ECA), que fazia referência às penalidades dos meios de comunicação por exposição indevida do público infanto-juvenil, qual seja “[...] ou a suspensão da programação da emissora até por dois dias, bem como da publicação do periódico até por dois números" (BRASIL, 1989). No julgamento, inclusive, foi enfatizado que as restrições à liberdade em tela devem estar, explícita ou implicitamente, previstas no próprio texto da Constituição (STF, 1999).

Da mesma forma que é importante assegurar o exercício livre do direito de informar via meios de comunicação, torna-se necessário assegurar o respeito à honra, à intimidade e à privacidade, bem como outros direitos fundamentais do Estado Democrático brasileiro . Devese, assim, buscar sempre a conciliação e a harmonização desses direitos.

\footnotetext{
Numa sociedade democrática, ninguém deve ser o único árbitro dos limites das conveniências quanto ao respeito aos direitos, pois tal privilégio seria uma concessão totalitária, semelhante à do monarca absolutista, que só se submetia ao julgamento de sua própria consciência (DALLARI, 2001, p. 2).
}

As limitações da liberdade de informação jornalística num sistema jurídico, por ma is liberal que este seja, "se justificam por não ser tal liberdade um fim em si mesmo" (CALDAS, 1997, p. 108). A justificativa real do Estado Democrático de Direito considera o direito à informação como meio de promoção da pessoa, a qual "é o centro gravídico e a razão última da ordem jurídica do país" (CALDAS, 1997, p. 108).

\footnotetext{
${ }^{3}$ EMENTA: AÇÃO DIRETA DE INCONSTITUCIONALIDADE. LEI FEDERAL 8069/90. LIBERDADE DE MANIFESTAÇÃO DO PENSAMENTO, DE CRIAÇÃO, DE EXPRESSÃO E DE INFORMAÇÃO. IMPOSSIBILIDADE DE RESTRIÇÃO [...]. 2. Limitações à liberdade de manifestação do pensamento, pelas suas variadas formas. Restrição que há de estar explícita ou implicitamente previs ta na própria Constituição. Ação direta de inconstitucionalidade julgada procedente (STF, 1999, grifo nosso).
} 
Considerando os objetivos desta pesquisa, pretende-se examinar, nos próximos tópicos, aspectos dos limites internos e externos da liberdade da informação jornalística, segundo a classificação doutrinária majoritária ${ }^{4}$.

\subsection{Limites Internos}

De acordo com Pedro Frederico Caldas (1997, p. 108), os limites internos da liberdade da atividade jornalística estão relacionados com as responsabilidades sociais e o compromisso com a verdade, isto é, "os meios de comunicação devem aceitar e cumprir certas obrigações para com a sociedade, estabelecendo um alto nível profissional e de informação, com base na veracidade, na exatidão, na objetividade e no equilibrio " (CALDAS, 1997, p. 108).

No Estado Democrático de Direito, observa-se que, para o exercício do direito de ser informado, já não basta a simples existência da informação: é imprescindível a busca pela informação correta (STROPPA, 2010, p. 163).

No mesmo sentido, José Afonso da Silva afirma que:

O dono da empresa e o jornalista têm um direito fundamental de exercer sua atividade, sua missão, mas especialmente têm um dever. Reconhece-se-lhes o direito $\underline{\text { de informar ao público os acontecimentos e ideias, mas sobre ele incide o dever de }}$ informar à coletividade de tais acontecimentos e ideias, objetivamente, sem alterarlhes a verdade ou es vaziar-lhes o sentido original, do contrário, se terá não informação, mas deformação (SILVA, 1998, p. 250, grifo original).

Para esclarecer tal entendimento, tona-se necessário retomar a diferenciação doutrinária entre notícia e crítica, tendo em vista a sua utilidade prática na delimitação de parâmetros e critérios no exercício democrático da informação jornalística. Apesar de certas semelhanças, a notícia e a críica guardam particularidades e contornos jurídicos distintos, que, muitas vezes, podem exigir o uso do critério da preponderância como forma de individualização de uma ou outra modalidade à luz do caso concreto (STROPPA, 2010, p. 183).

\footnotetext{
${ }^{4}$ Pedro Frederico Caldas (1997, pp. 105-112); Tatiana Stroppa (2010, pp. 160-197); Luís Roberto Barroso (2007, pp.84-87), entre outros, adotam, direta ou indiretamente, a classificação de limites internos e externos sobre os limites da liberdade de imprensa ou liberdade informação jornalística.
} 
A notícia é toda nota, ou anotação, sobre fato ou pessoa (NUNES JÚNIOR, 1967, p. 38). 'Em suma, são aqueles fatos cujo conhecimento é necessário para que o indivíduo tenha concreta participação da vida coletiva de determinada sociedade” (NUNES JÚNIOR, 1967, p. $38)$.

A elaboração da notícia, nesse sentido, deve considerar critérios adequados para que possa receber tratamento constitucional assegurado às informações de caráter jornalístico . Dentre esses critérios, destacam-se a veracidade e a abordagem de fatos de interesse público.

Sem desconsiderar a falta de objetividade do conceito de verdade (LOPES, 1997, p. 207), o que se almeja ao exigir dos órgãos de informação compromisso com a verdade é a diligência em apurá-la. Deve-se evitar, a todo custo, a despreocupação e a irresponsabilidade em publicar ou divulgar algo que não resista a uma simples aferição (CARVALHO, 1999, p. 97). Com isso, espera-se que a notícia não seja objeto de distorções intencionais, nem de nítida predisposição em induzir o público ao erro (LOPES, 1997, p. 208).

É certo afirmar, então, que a meta dos jornalistas deve ser perseguir a verdade sobre os fatos (STROPPA, 2010, p. 172), e a garantia de uma "pluralidade das fontes da informação" (LOPES, 1997, p. 206) é o melhor caminho para se acançá-la.

$\mathrm{Na}$ notícia, da circunstância de destinar-se a dar ciência da realidade, decorre a existência da verdade - um requisito interno, mais do que um limite, já que só se estará diante de uma informação de cunho jornalístico, digna de proteção nesses termos, quando a verdade, mesmo que relativizada, estiver presente (BARROSO, 2007, p. 85).

Por mais que pareça óbvio o dever de uma informação verdadeira por parte da atividade jornalística, não são poucos os casos de manipulação no trato da notícia apontados pela doutrina. A título de exemplo, citam-se a cobertura das eleições presidenciais do Brasil de 1989, na qual a Rede Globo, ao invés de exibir no Jornal Nacional um resumo do debate entre Collor e Lula, apresentou um falso recorte, com os melhores momentos de um candidato e os piores de outro (CARVALHO, 1994, p. 93), bem como o canal francês La5 que organizou um ataque violento de skinheads contra um africano com o objetivo de obter imagens exclusivas do evento (FERREIRA Apud STROPPA, 2010, p. 169).

A notícia também deve atender ao interesse público, ou seja, a assuntos relacionados "às escolhas que a pessoa deve fazer, como membro de uma comunidade, que interessem às demais e nelas interfiram, bem como que influenciam no que pertine à sua organização política e social" (CARVALHO, 1999, p. 149). 
Ainda sobre o interesse público, Luís Roberto Barroso (2007, p. 86) alerta para a necessidade de cuidado ao se considerar essa questão como limite da liberdade de informação. Para este autor, o interesse público, além de possuir um conteúdo subjetivo (isto é, juízo de valor sobre a importância de determinada informação ou opinião), guarda um interesse de maior relevância que advém da própria noção de liberdade em si independentemente de qualquer conteúdo (BARROSO, 2007, p. 86). Assim, o interesse público na divulgação de qualquer fato verdadeiro, em regra, torna-se presumido (BARROSO, 2007, p. 89).

A crítica na atividade jornalística, por sua vez, "é o exame valorativo, em que se apontam a perfeição e as deficiências do fato noticiado" (NUNES JÚNIOR, 1966, p. 39). São “fatos que se transmitem à opinião pública - logicamente unidos aos inevitáveis juízos de valor e opiniões, já que a informação não pode ser asséptica ou neutra - e, ademais têm um caráter noticioso, isto é, de interesse social” (SORIANO Apud NUNES JÚNIOR, 1967, p. 40).

Mesmo mantendo o víncub com o fato noticiado, a críica é mais abrangente do que a notícia, uma vez que não se exige daquela o compromisso com a veracidade, haja vista que ideias e opiniões, pela sua própria natureza, não estão sujeitas à demonstração de exatidão ou verossimilhança (STROPPA, 2010, p. 178).

A Lei de Imprensa, no mesmo sentido que considera o direito de crítica jornalíst ica com elástica liberdade, no seu artigo 27 , inciso $\mathrm{I}^{5}$, exclui tal modalidade das causas sobre eventuais abusos à liberdade de manifestação de pensamento e de informação (GODOY, 2001, p. 101).

Não cabe à críica jornalística, contudo, o exercício irrestrito, ilimitado. Esta, nas palavras de Lauro Limborço (1986, p. 453), deve se constituir num "ponto de equilibrio entre dois extremos, ambos reprováveis: de um lado, a bajulação, e, do outro, a injúria”. Ou, em termos diferentes:

\section{[...] Quando sob o pretexto de crítica se apresentem artigos que exprimem a afronta ou provocam o ridículo e revelam que foram ditados com o fim de desacreditar e injuriar - então já não es tamos no caso de antederà sombra da crítica, por que a injúria é manifesta (TURIM Apud MIRANDA, 1995, pp. 478-479).}

Desse modo, a crítica não pode sobrepor-se indevidamente, por exemplo, aos direitos da personalidade do cidadão comum ou aos aspectos íntimos da pessoa pública quando caracterizam simples insulto à sua dignidade.

\footnotetext{
5 A Lei de Imprensa, Lei de $N^{\circ}$. 5.250, afirma que: Artigo 27. Não constituemabusos no exercício da liberdade de manifestação do pensamento e de informação: I - a opinião desfavorável da crítica, literária, artística, científica ou desportiva, salvo quando inequívoca a intenção de injuriar ou difamar; [...]” (BRASIL, 1967, grifo nosso)
} 


\subsection{Limites externos}

Os limites externos da liberdade de informação jornalística "encontram muros justamente nos limites de outros direitos de igual hierarquia constitucional" (CALDAS, 1997, p. 108).

Neste tópico, dentro do escopo do presente artigo, examinam-se situações propostas na doutrina ou na jurisprudência, em que os limites constitucionais externos à liberdade de informação jornalística são impostos a partir do contato com os direitos da personalidade ou outros direitos de igual status na Constituição de 1988.

\subsubsection{Proteção à identidade da pessoa investigada por fato criminoso}

A doutrina e a jurisprudência, de forma recorrente, tem abordado o conflito entre a proteção dos direitos da personalidade de pessoas investigadas e a exposição pelos meios de comunicação, seja no momento da apuração de fatos criminosos ou posteriormente.

Para contextualizar tal situação, menciona-se o "Caso da Escola Base", que faz referência à cobertura da imprensa brasileira sobre um suposto crime de abuso sexual praticado contra alunos de uma escola infantil, na cidade de São Paulo, em março de 1994. Os acusados eram os donos da escola, ou pessoas ligadas a eles, que foram alvos de uma prática de jornalismo sensacionalista, associada, em certa medida, a uma condução irresponsável do inquérito por parte da Polícia Civil do estado de São Paub.

Poucos dias após o recebimento da denúncia do crime pelas autoridades, as manchetes dos jornais já sentenciavam os acusados e provocavam a ira da população: "Uma escola de horrores", "Perua escolar carregava crianças para orgia no maternal do sexo", "Tias torturavam crianças na escola do sexo", "Kombi era motel na escolinha do sexo" (RIBEIRO, 1995, p. 147). O resultado das investigações, por outro lado, concluiu pela inocência de todos os acusados (RIBEIRO, 1995, p. 145).

Anos mais tarde, o Superior Tribunal de Justiça reconheceu os equívocos cometidos no inquérito e na ação dos meios de comunicação sobre a "divulgação temerária da prática de abuso sexual contra alunos da escola base" ${ }^{\prime 6}$ (STJ, 2004). 
A questão em tela não é negar a possibilidade do jornalismo de divulgar notícias que tenham relação com fatos criminosos. Sabe-se que o crime, além de um caráter pessoal, possui também, por natureza, uma dimensão de interesse social (GODOY, 2001, p. 88), uma vez que envolve questões de segurança pública, pertinente à toda coletividade. Mas, pretendese chamar a atenção para as consequências e os limites dessa atividade jornalística.

No caso de pessoas investigadas, o jornalista, em decorrência do princíp io constitucional da presunção de inocência (Artigo $5^{\circ}$, inciso LVII), precisa ter maior cautela na divulgação de fatos penais que não foram totalmente apurados (GODOY, 2001, p. 90).

Sobre tal ponto, considera-se, ainda, a prática de aguns profissionais da mídia de “interrogar" previamente o investigado, o que pode afrontar, dentre outros direitos, o seu direito constitucional de permanecer calado ou de não produzir prova contra si próprio, conforme previsão do artigo 5º inciso LXIII, da CR/1988 (SOUZA, 2008, pp. 160-161).

Não sem razão, a Delegacia-Geral da Polícia Civil do estado de São Paulo, editou, nos últimos anos, um conjunto de portarias ${ }^{7}$ com o intuito de coibir a submissão de presos ou suspeitos a entrevistas por eles não expressamente consentidas (SOUZA, 2008, p. 196).

\subsubsection{Atos e locais públicos versus vida privada}

Atos ocorridos em local público, em comparação com ambientes privados, reservados, possuem menor proteção jurídica no âmbito do direito à privacidade das pessoas.

Nesse sentido, destaca-se o entendimento de Capelo de Sousa:

\footnotetext{
6 EMENTA:RECURSO ESPECIAL. RESPONSABILIDADECIVIL DO EST ADO. DANO MORAL. ATO PRATICADO POR DELEGADO DE POLÍCIA. DIVULGAÇÃO TEMERÁRIA DA PRÁTICA DE ABUSO SEXUAL CONTRA ALUNOSDA ESCOLA DE BASE. NOT ÍCIA POSTERIORMENTE DESMENTIDA. AUMENTO DO VALOR FIXADO PELA CORTE DEORIGEM. POSSIBILIDADEDE REVISÃO POR ESTE SUPERIOR TRIBUNAL DE JUSTIÇA [...] (STJ, 2004).

7 A PORT ARIA DE N 18, DE 25.11.1998, DA DELEGACIA-GERAL DA POLÍCIA CIVIL DE SÃO PAULO AFIRMA, NO PARÁGRAFO PRIMEIRO, DO ARTIGO 11: “ASPESSOASREFERIDAS NESSE ARTIGO, APÓS ORIENTADAS SOBRE SEUS DIREIT OSCONST ITUCIONAIS, SOMENTE SERÃO FOTOGRAFADAS, ENT REVISTADASOU TERÃO SUASIMAGENSPOR QUALQUER MEIO REGISTRADAS, SE EXPRESSAMENTE O CONSENTIREM MEDIANTE MANIFESTAÇÃO EXPLÍCITADE VONT ADE, POR ESCRITO OU POR TERMO DEVIDAMENTE ASSINADO, OBSERVANDO-SE AINDA ASCORRELATAS NORMASEDIT ADASPELOS JUÍZOSCORREGEDORESDA POLÍCIA JUDICIÁRIA DAS COMARCAS" (SÃO PAULO APUD SOUZA, 2008,P. 218).
} 


\begin{abstract}
É menor a intensidade da tutela nos casos em que a vida privada dos indivíduos é adjacente à esfera pública dos mesmos, nomeadamente, quando o indivíduo se movimenta em lugares públicos, como estradas, restaurantes, praias, cerimônias públicas, recintos culturais (teatro, cinema, ópera, etc.) ou desportivos, mas em que a privacidade da sua vida impõe mesmo aí uma certa reserva (SOUSA, 1995, p. 327).
\end{abstract}

Eventos ocorridos no interior do domicílio de uma pessoa, em regra, não são passíveis de divulgação contra a vontade dos indivíduos. Todavia, tornam-se fatos noticiáveis, aqueles que acontecem na rua, na praia, ou mesmo em lugar de acesso público, como um restaurante ou um saguão de hotel (BARROSO, 2007, p. 89).

Pedro Frederico Caldas (1997, p. 103) lembra que é comum na cobertura da imprensa de atos públicos, como comícios sindicais ou desfiles de escola de samba, que pessoas anônimas sejam registradas em vídeos e fotos. Por mais que essas pessoas não tivessem a intenção de se expor, na prática, acaba por prevalecer o interesse geral sobre a divulgação de determinado acontecimento público.

Tal entendimento pode ser diferente desde que a composição da foto ou do vídeo divulgado busque, de maneira clara, a identificação da pessoa ao invés do ato público, capaz de gerar uma situação de invasão de privacidade, pela qual caberá indenização (CARVALHO, 1994, p. 39). Em outros termos, quando o registro da presença de anônimo desloca a pessoa para o "centro gravídico da matéria veiculada", esta hipótese poderá apresentar uma violação do direito à privacidade (CALDAS, 1997, p. 104).

\title{
4.2.3 Pessoas públicas, célebres ou notórias
}

Nesse tópico, serão considerados dois grupos: as pessoas públicas e as pessoas célebres ou notórias. O primeiro corresponde a governantes e representantes públicos, altos dignitários da justiça, administradores de instituições e órgãos públicos, líderes de sindicatos e associações. O segundo grupo, de escopo mais genérico, inclui o líder políico ou empresarial, o astro do rock, o herói, o desportista de relevância, etc. (CALDAS, 1997, p. 104).

As pessoas públicas e célebres têm o seu direito de privacidade tutelado em intensidade mais branda em comparação com as pessoas comuns (BARROSO, 2007, p. 89), como se os limites da sua vida reservada recuassem para fronteiras mínimas (CALDAS, 1997, p. 104). 
Isso não significa, contudo, o "aniquilamento" (GODOY, 2001, p. 82) dos direitos da personalidade dessas pessoas, mas apenas que possuem um campo de tutela jurídica menor do que as pessoas comuns ou sem notoriedade.

Na relação entre pessoas públicas e os direitos da privacidade, a liberdade de informação jornalística tem como última fronteira o interesse público. O que é muito diferente da mera bisbilhotice e curiosidade, que não se enquadram no exercício constitucional do direito à informação jornalística (STROPPA, 2010, p. 196).

Nesse sentido, Paul Johnson, escritor e jornalista inglês, propõe uma fórmula para que os jornalistas possam delimitar a linha que separa a vida privada da pública, consistente na realização do seguinte questionamento pelo profissional: esta revelação é feita claramente no interesse público? (FRANCO Apud STROPPA, 2010, p. 196, grifo nosso). Frisa-se que uma informação feita em atendimento ao interesse público tem sentido totalmente distinto daquela que possa ser interessante para o público (FRANCO Apud STROPPA, 2010, p. 196).

No ambiente familiar, por exemplo, as pessoas públicas e notórias devem ter preservada a proteção do direito à privacidade, como uma "área nuclear invio lável" (GODOY, 2001, p. 82). Exemplo disso é a exposição de uma famosa atriz, que, fotografada no interior da sua casa com uso de câmeras de alta tecnologia, tem seus direitos violados quando tais fotos são publicadas numa revista (CARVALHO, 1994, p. 36). Mesmo que seja uma pessoa pública, ela não deixa de possuir direitos da personalidade, dentre os quais, aqueles relativos ao direito à privacidade e a sua própria imagem.

Ademais, não se concebe que os direitos da personalidade de pessoas públicas e célebres possam ser afrontados para fins exclusivamente comerciais. Em tais hipóteses, desvirtua-se qualquer interesse jornalístico para dar lugar ao interesse publicitário, o que não justifica o mesmo conteúdo de liberdade atribuído (GODOY, 2001, p. 83).

Isso pode ser ilustrado na seguinte citação:

O seminário L'Express, em seu número 6 de abril de 1970, publicou a fotografia do presidente francês Georges Pompidou a bordo de um barco equipado com motor Mercury, acrescida de um texto publicitário com os seguintes dizeres: "Se durante dez anos nos esforçamos em ganhar as competições, o fazemos por sua segurança, Sr. Presidente". A revista foi processada e o Tribunal Francês proclamou que toda pessoa tem direito exclusivo sobre a sua imagem e seu uso, ordenando a proibição do anúncio (COSTA JÚNIOR Apud STROPPA, 2010, p. 192). 


\subsubsection{Valores éticos e sociais}

No caso particular de programas de emissoras de rádio e televisão, a Constituição da República de 1988, no seu artigo 221, inciso IV, fez questão de impor a esses meios de comunicação restrições no que dizem respeito aos valores éticos, morais, religiosos e dos bons costumes, adotando a seguinte redação:

Art. 221. A produção e a programação das emissoras de rádio e televisão atenderão aos seguintes princípios: I - preferência a finalidades educativas, artísticas, culturais e informativas; II - promoção da cultura nacional e regional e estímulo à produção independente que objetive sua divulgação; III - regionalização da produção cultural, artística e jornalística, conforme percentuais estabelecidos em lei; IV - respeito aos valores éticos e sociais da pessoa e da família (BRASIL, 1988, grifo nosso).

Os princípios do artigo 221, desse modo, norteiam a produção e a programação das emissoras de rádio e televisão (STROPPA, 2010, p. 107), destacando a função social desses veículos para a consolidação de objetivos caros à democracia brasileira.

Os três incisos iniciais são normas programáticas, "que estabelecem apenas uma finalidade, um princípio", sem impor ao egislador "a tarefa de atuá-las", apenas requerendo "uma política pertinente à satisfação dos fins positivos nelas indicados" (SILVA, 2003, pp. 82-83).

O inciso IV, por outro lado, desde logo, investe a sociedade na situação de exigir o cumprimento do texto constitucional. $\mathrm{O}$ que não deixa de ser uma tarefa complexa na aplicação da ki, tendo em vista que o alto grau de indeterminação dos conceitos previstos nesse inciso pode dificultar o seu enquadramento legal

Sobre o artigo 221, inciso IV, cita-se decisão do Tribunal de Justiça do estado do Rio de Janeiro:

ACAO CIVIL PUBLICA. FILME. VEDACAO DE TRANSMISSAO TELEVISIONADA. ART. 221, INC. IV. CONSTITUICAO FEDERAL DE 1988. MANDADO DE SEGURANCA. Transmissão de filme de forte conteúdo em cenas de sexo explicito, violência excessiva e brutal, comprometedor de valores éticos, por transmissão televisionada. Vedação amparada em preceptivo constitucional (art. 221, inc. IV, da Constituição Federal). Cabe ao Poder Jurisdicional o controle e a preservação dos valores morais, sob cujas bases se edificam a sociedade e a família brasileira, evitando que transmis sões, em circuito aberto, penetrem nos lares indefesos, confundindo o ético com a liberdade sem freios, o licencioso com a arte cinematográfica. Segurança denegada (TJRJ, 1992, grifo nosso). 


\subsubsection{Proteção à infância e à Juventude}

O Direito da Criança e do Adolescente, num processo iniciado com a Constituição da República de 1988, tem se consolidado como ramo autônomo do direito brasileiro, formado por uma rede de proteção com variados diplomas legais e normativos em geral dos quais se destaca a Lei $\mathrm{n}^{\circ}$ 8.069, de 13 de julho de 1990 - o Estatuto da Criança e do Adolescente (ECA) (DUPRET, 2010, p. 21).

O ECA, cuja validade constitucional é alinhavada pelas mudanças dos direitos humanos da criança e do adolescente em ordem internacional, levou a sério a Convenção das Nações Unidas sobre os Direitos da Criança, de 1989, na medida em que estabelece uma nova lógica de direitos e garantias (RAMIDOFF, 2011, p. 31), bem como acolhe a concepção de desenvolvimento integral da criança.

Dessa forma, as crianças e adolescentes devem ter garantida uma vida digna, livre de violência, bem como a preservação da sua integridade física e psicológica, para que possam desenvolver de forma saudável sua personalidade (CARDIN; MOCHI, 2012, p. 13.464). Em razão disso, a tutela da infância e da juventude há de ser considerada entre os direitos da personalidade (CURY JÚNIOR, 2006, pp. 84-85).

No âmbito da solução de colisão de direitos fundamentais, envolvendo, por exemplo, restrições de direitos da personalidade e da liberdade de informação jornalística, há de analisar o caso concreto a partir da constatação de um direito da personalidade especial, peculiar às pessoas em desenvolvimento e amparado nos princípios de proteção integral e da maior vulnerabilidade (CURY JÚNIOR, 2006, p. 85).

É por efeito da proteção à dignidade da criança e do adolescente que, em situações relativas à liberdade de imprensa e à divulgação de atos judiciais, administrativos ou policia is sobre criança ou adolescente, o direito a informação jornalística encontra a limitação necessária para colocar a criança e o adolescente a salvo de qualquer tratamento desumano, vexatório ou constrangedor (FERREIRA, 2008, p. 41).

Nelson M. de Moraes Rego (2002, p. 5), de forma conclusiva, afirma que, através dos artigos 15 a 18 do Estatuto da Criança e do Adokscente, duas novas categorias de cidadãos são estratificadas solidamente: a "criança-cidadão" e o "adolescente-cidadão", dotadas de proteção e reconhecimento de uma cidadania própria e especial. 
Não são poucos, entretanto, exemplos de violações de direitos das crianças e dos adolescentes no campo da comunicação de massa, que acabam por apontar a baixa qualidade da cobertura jornalística e o cotidiano desrespeito dos direitos do público infanto -juvenil.

Diariamente, a sociedade vê-se diante de grande quantidade de notícias e ideias difundidas por múltiplos veículos de comunicação que, por vezes, acabam violando direitos fundamentais durante a cobertura de um fato. Em diversas ocasiões, nota-se a exibição de crianças e adokscentes de maneira sensacionalista pelos programas da TV aberta, associados aos temas da violência ou da erotżação infantil como espetáculo para gerar audiência e arrecadar recursos financeiros.

De modo geral, a infância e a adolescência, no âmbito da atividade jornalística, é assunto que merece cautela, ao passo que a abordagem irresponsável por parte de um veículo de comunicação pode constranger e gerar impactos duradouros para a vida da criança ou do adolescente (VIVARTA, 2011, p. 55).

\section{CONSIDERAÇÕES FINAIS}

A reflexão sobre o direito fundamental à informação e o atual papel da atividade jornalística não pode mais ser compreendida a partir de uma concepção exclusivamente liberal, na medida em que não se justificam como um fim em si mesmo. No Estado Constitucional brasileiro, em que prevalece o paradigma do Estado Democrático de Direito, a justificativa real da liberdade de informação jornalística deve considerar o meio de promoção da pessoa, em que o "núcleo central" do sistema jurídico é a dignidade da pessoa humana.

Desse modo, no âmbito de liberdades e garantias constitucionais, como é caso da liberdade de informação jornalística, admite-se não apenas a proteção jurídica negativa, mas também a positiva, pela qual o poder estatal pode contribuir na organização, na regulação e na prestação de ações que têm em vista a função social dos meios de comunicação.

A liberdade de informação jornalística, em substituição ao termo liberdade de imprensa, representa a difusão de informações e opiniões por todos os meios de comunic ação de massa, independentemente dos seus formatos.

O Brasil, na mesma tendência de outros países do ocidente, e, na esteira da Declaração Universal de Direitos Humanos (DUDH), reconhece na sua Carta Política o valor 
dos meios de comunicação para a manutenção de uma sociedade bem informada e a indispensabilidade da liberdade de informação jornalística.

Todavia, mesmo com a amplitude da liberdade assegurada no texto constitucional, vale enfatizar que o direito constitucional de liberdade da informação jornalística não é absoluto, na medida em que encontra limites na própria Constituição de 1988.

Tais limites são classificados pela doutrina majoritária como internos e externos. Os limites internos representam o respeito às responsabilidades sociais e o compromisso com a verdade da informação. Os limites externos, por sua vez, estabelecem uma relação entre a liberdade de informação jornalística e os outros direitos, de igual hierarquia constitucional, como é o caso da proteção da dignidade da pessoa investigada, a proteção relativa do direito de privacidade de pessoas públicas ou célebres, o respeito aos valores éticos, morais, religiosos e dos bons costumes nos programas de TV e rádio, a proteção integral ao direito de crianças e adolescentes, entre outros.

Em suma, a liberdade de informação jornalística irrestrita não se coaduna com a interpretação do sistema jurídico brasileiro, que, considerando a sua dimensão constitucional, deve observar limites típicos da atividade do jornalismo ou que tenham relação direta com outros direitos igualmente fundamentais para o indivíduo e a coletividade.

\section{REFERÊNCIAS BIBLIOGRAFICAS}

BARROSO, Luís Roberto. Liberdade de expressão versus direitos da personalidade: Colisão de direitos fundamentais e critérios de ponderação. In: SARLET, Ingo Wolfgang (org.). Direitos Fundamentais, informática e comunicação: agumas aproximações. Porto Alegre: Livraria do Advogado, p. 63-100, 2007.

BOBBIO, Norberto. A era dos direitos. Rio de Janeiro: Campus, 1992.

BONAVIDES, Paulo. Constituição aberta. Belo Horzonte: Del Rey, 1993.

BRASIL. Lei n. 5.250/1967, que regula a liberdade de manifestação do pensamento e de informação. Publicada no Diário Oficial da União, de 11 de fevereiro de 1967.

Constituição (1988). Constituição da República Federativa do Brasil. Disponível em <http//www.planalto.gov.br/ccivil_03/constituicao/constituicaocompilado.htm〉. Acesso em: 05 de jul 2015. 
Superior Tribunal de Justiça. REsp. 351779 SP, Rel Min. Elaina Calmon, julgado em 19/11/2002, DJ 09/02/2004. Disponível em: <www.stj.jus.br>. Acesso em 10 ago. de 2015.

Supremo Tribunal Federal ADIn 890-2 DF, Rel Ministro Ilmar Galvão, julgado em: 04/09/1999, Dj 04/06/2004. Disponível em:<www.stf.jus.br>. Acesso em 10 de ago. de 2015. BRASIL. Supremo Tribunal Federal ADPF 130 DF, Rel Min. Carlos Ayres Britto, julgado em: 05/11/1999, Dj 01/01/2012. Disponível em <www.stfjus.br>. Acesso em 10 ago. de 2015 .

CALDAS, Pedro Frederico. Vida Privada, Liberdade de Imprensa e Dano Moral. São Paulo: Saraiva, 1997.

CARDIN, Valéria Silva Galdino; MOCHI, Tatiana de Freitas Giovanni. Dos limites da liberdade de imprensa diante dos direitos fundamentais da criança e do adolescente. 2012. Disponível em:<http //galdino.adv.br/site/artigos/>. Acesso em 10 de jul 2015.

CARVALHO, Luís Gustavo Grandinetti Castanho de. Direito de informação e liberdade de expressão. Rio de Janeiro: Renovar, 1999.

CARVALHO, Luís Gustavo Grandinetti Castanho de. Liberdade de informação e o direito difuso à informação verdadeira. Rio de Janeiro: Renovar, 1994.

CRUZ, Álvaro Ricardo de Souza. Processo Constitucional e a Efetividade dos Direitos Fundamentais. In: SAMPAIO, José Adércio Leite Sampaio; CRUZ, Álvaro Ricardo de Souza (Coord). Hermenêutica e Jurisdição Constitucional. Belo Horizonte: Del Rey, 2001. p. 195246.

DALLARI, Dalmo de Abreu. Liberdade e intimidade: direitos fundamentais. Folha de S. Paulo, São Paulo, 06 ago. 2001. Disponível em: <http//www1.fo lha.uol.com.br/fsp/opiniao/fz0608200109.htm>. Acesso em: 05 ago. 2015.

DUPRET, Cristiane. Curso de Direito da Criança e do Adolescente. Belo Horizonte, Ius: 2010.

FERREIRA, Aloízio. Direito à informação, direito à comunicação: direitos fundamentais na Constituição brasileira. São Paulo: Instituto Brasileiro de Direito Constitucional, 1997.

GODOY, Chudio Luiz Bueno de. A Liberdade de Imprensa e os Direitos da Personalidade. São Paulo: Athas, 2001. 
GUERRA, Sidney. Breves considerações sobre os limites da liberdade de imprensa. Revista Faculdade de Direito de Campos, ano VI, nº 6, Jun. 2005.

HONÓRIO, Cláudia et. al. ADPF 130: A proteção dos direitos fundamentais à liberdade de imprensa e de expressão por meio do controle jurisdicio nal de normas pré-constitucionais. 2008. Disponível em:

$<$ http $/ /$ www.conpedi.org.br/manaus/arquivos/anais/salvador/ana_lucia_pretto_pereira-1.pdf $\$$. Acesso em: 05 ago. 2015.

CURY JÚNIOR, David. A proteção jurídica da imagem de crianças e adolescentes. 2006. 284f. Tese (Doutorado) - Pontifícia Universidade Católica de São Paulo, Programa de PósGraduação em Direito. São Paulo.

LEÃO, Anís José. Limites da liberdade de imprensa. Belo Horizonte: Editora Revista brasileira de estudos políicos, 1961.

LIMBORÇO, Lauro. O direito de crítica e a lei de imprensa. Revista dos Tribunais, São Paulo, n. 606, 1986.

LOPES, Vera Maria de Oliveira Nusdeo. O direito à informação e as concessões de rádio e televisão. São Paulo: Editora Revista dos Tribunais, 1997.

MARCONDES FILHO, Ciro. Imprensa e capitalismo. São Paub: Kairós, 1984.

MIRANDA, Darcy de Arruda. Comentários à lei de imprensa. 3. ed. São Paulo: Revista dos Tribunais, 1995.

. Dos abusos da liberdade de imprensa. São Paub: Revista dos Tribunais, 1959.

NOBRE, Freitas. Imprensa e liberdade: os princípios constitucionais e a nova legislação. São

Paulo: Summus, 1988.

NUNES JÚNIOR, Vidal Serrano. A proteção constitucional do direito à informação e o direito à crítica jornalística. São Paub: FTD, 1997.

ONU. Declaração Universal dos Direitos Humanos (1948). Disponível em: $<$ http $/ /$ www.dudh.org.br/>. Acesso em 05 de ago. 2015. 
RABAÇA, C. A; BARBOSA, G. G. Dicionário da comunicação. 2. ed. Rio de Janeiro: Campus, 2001.

RAMIDOFF, Mário Luiz. Lições de direito da criança e do adolescente. Ato infracio nal e medidas socioeducativas. 3. ed. Curitiba: Juruá, 2011.

REGO, Nelson M. de Moraes. Proteção Constitucional da Criança e do Adolescente, Vulnerabilidade e Gênero no Sistema de Direito Brasileiro: algumas reflexões dialogais. 2012. Disponível em: <http://www.osconst itucionalistas.co mbr/protecao-constitucional-dacrianca-e-do-adolescente>. Acesso em 05 ago. 2015.

RIBEIRO, Alex. Caso Escola Base: os abusos da imprensa. São Paub: Ática, 1995.

RIO DE JANEIRO. Tribunal de Justiça do estado do Rio de Janeiro. ACP, Rel Desembargador Ellis Hermydio Figueira, julgado em: 10/09/1992. Disponível em: $<$ http://www.tjrj.jus.br>. Acesso em 05 de ago. 2015.

SILVA, José Afonso da. Aplicabilidade das Normas Constitucionais. 6.ed. São Paulo: Malheiros, 2003.

SILVA, Tadeu Antônio Dix. Liberdade de Expressão e Direito Penal no Estado democrático de Direito. São Paulo: IBCRIM, 2000.

SOUSA, Rabindranath V. A. Capelo de. O direito geral da personalidade. Coimbra: Coimbra Editora, 1995.

SOUZA, Sérgio Ricardo de. Controle Judicial dos Limites Constitucionais à Liberdade de Imprensa. Rio de Janeiro: Editora Lumen Juris, 2008.

STROPPA. Tatiana. As dimensões constitucionais do direito de informação e o exercício da liberdade de informação jornalística. Belo Horionte: Fórum, 2010.

VIVARTA, Veet (coord.). Infância e comunicação: referências para o marco legal e as políticas públicas brasileiras. Brasilia: ANDI, 2011. 